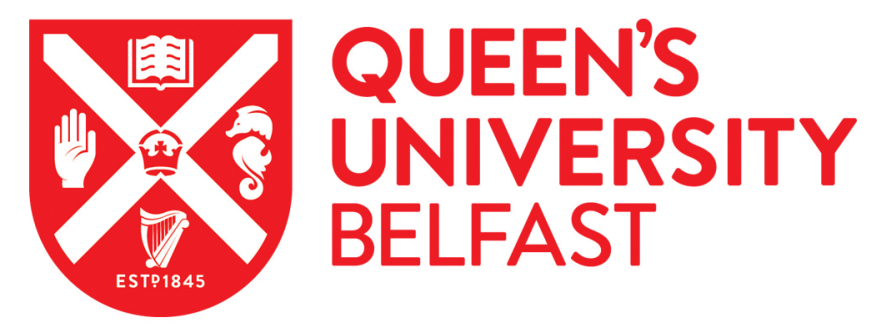

\title{
The EU Clinical Trials Regulation: Key Priorities, Purposes and Aims and the Implications for Public Health
}

Flear, M. L. (2016). The EU Clinical Trials Regulation: Key Priorities, Purposes and Aims and the Implications for Public Health. Journal of Medical Ethics, 42(3), 192-198. https://doi.org/10.1136/medethics-2015-103258

Published in:

Journal of Medical Ethics

Document Version:

Peer reviewed version

Queen's University Belfast - Research Portal:

Link to publication record in Queen's University Belfast Research Portal

Publisher rights

(c) 2016 The Authors

\section{General rights}

Copyright for the publications made accessible via the Queen's University Belfast Research Portal is retained by the author(s) and / or other copyright owners and it is a condition of accessing these publications that users recognise and abide by the legal requirements associated with these rights.

Take down policy

The Research Portal is Queen's institutional repository that provides access to Queen's research output. Every effort has been made to ensure that content in the Research Portal does not infringe any person's rights, or applicable UK laws. If you discover content in the Research Portal that you believe breaches copyright or violates any law, please contact openaccess@qub.ac.uk. 


\title{
The EU Clinical Trials Regulation: Key Priorities, Purposes and Aims and the Implications for Public Health
}

\author{
Mark L Flear*
}

\section{Introduction}

The replacement of the European Union (EU) Clinical Trials Directive ${ }^{[1]}$ (CTD) by the new Clinical Trials Regulation $^{[2]}$ (CTR), which entered into force on 16 June 2014 but will not apply before 28 May 2016 (Article 99 CTR), ${ }^{1}$ provides an opportunity to review the legal and political context within which this important aspect of research law and policy sits and reflect on the implications for public health. This article therefore supplements the two more detailed considerations of specific aspects of the CTR in this issue. ${ }^{[3]}$ My aim is to relate the context to the key purposes and aims of EU law and policy on clinical trials ${ }^{2}$ in order to explain and clarify its orientation. On that basis I build on my previous work ${ }^{[4-5]}$ to argue that the CTR and the changes it introduces to the law on clinical trials are part of the EU's continued focus on market optimisation. It is this focus that orients and directs the pharmaceutical development pipeline as a whole, but that undermines the achievement of key public health objectives.

Specifically, the CTR seeks to improve safety data production as the basis for licensing new products, supporting corporate profitability and optimising the economy. However, this overall focus feeds into the skewing of resources and attention towards pharmaceutical (often treatment-based) responses to public health problems (a process often referred to as 'pharmaceuticalisation'), but with detrimental consequences for public health. ${ }^{[6-7]}$ Consequences include the neglect of research and development in and the unavailability of pharmaceuticals that could tackle the biggest causes of mortality and morbidity globally ${ }^{[8]}$ (especially in the global South, ${ }^{3}$ a situation exacerbated by global patents $\left.{ }^{4}\right){ }^{[4-5]}$ In an era when communicable diseases tend to garner more resources and attention as threats to public health than non-communicable diseases, a focus on pharmaceutical-fixes might aggravate the effects of the social conditions that mean the latter loses out. ${ }^{5} \mathrm{~A}$ focus on pharmaceuticals also means that wider non-pharmaceutical (usually preventative) public health interventions that would tackle both communicable and non-communicable diseases receive less resources and attention, despite their being cheaper and more effective at producing better overall improvements in public health. ${ }^{6}$ The public health implications of the CTR are, therefore, an important ethical matter that might be overlooked without the attention to the wider legal and political context that this article provides.

\footnotetext{
${ }^{*}$ My thanks to Muireann Quigley for comments on earlier drafts. This article was written during a sabbatical during the 2015-16 academic year - my thanks to School of Law, Queen's University Belfast for this time to focus on research.

${ }^{1}$ The CTD continues to apply in a transitional period, see Article 98 CTR.

2 The law discussed here applies not only to the EU, but also the wider European Economic Area (or EEA). The EEA comprises the 28 Member States of the EU and three members of the European Free Trade Association (EFTA), Iceland, Liechtenstein and Norway. Switzerland, the fourth EFTA Member State, maintains an association agreement with the EEA. For the sake of simplicity the article refers to, for example, 'EU law'.

${ }^{3}$ The so-called 10/90 research gap in which only 10 per cent of global health research is spent on problems that affect 90 per cent of the global population, especially poverty-related diseases. The gap has narrowed slightly but remains a key concern.

${ }^{4}$ Provided under the Agreement on Trade-Related Aspects of Intellectual Property Rights (TRIPs). The public health friendly flexibilities under this framework are seldom used and are being undercut by so-called TRIPsplus agreements. Marrakesh Agreement Establishing the World Trade Organisation (WTO), opened for signature 15 April 1994, 1867 UNTS 3, annex 1C TRIPs (entered into force 1 January 1995). Under TRIPs it is for WTO Member States (which includes EU Member States) to determine what deserves to be patented, and as such countries in the industrialised global North, ie, where the biggest producers of pharmaceuticals have their homes, are effectively able to export their patent protections.

${ }^{5}$ As I argue in references [4-5] these conditions are apparent at the EU level, where (as elsewhere) risk and security frame the regulation of and interventions in public health.

${ }^{6}$ The argument advanced here is that the CTR represents a continuation of current focus and orientation, and for that reason it continues to undermine the achievement of public health objectives.
} 
The starting point for my account, in the next section, is to begin by noting the joint scientific and ethics-based rationale that is foregrounded in the CTR and then explaining how it is used to justify the adoption of an EU regulation. After which I outline the main changes introduced by the CTR. In the third section I deepen the discussion in order to underline the deeper (and less prominent) marketoriented purposes and aims of the CTR. In order to do so I explain how the CTR relates to the EU's programmatic priorities of creating a dynamic and innovative market-based economy and economic optimisation. I explain how those priorities are reflected in the alignment of the CTR to market authorisation as part of the pharmaceutical development pipeline. Finally, I discuss the way in which the legal basis for the CTR is used to set its market-oriented purposes and aims so as to meet those broader priorities.

\section{Introducing the EU Clinical Trials Regulation}

\section{A Clinical Trials and EU Law}

Clinical trials are a type of clinical research and therefore an important part of the pharmaceutical development pipeline ${ }^{7}$ or 'cycle of innovation'. This begins with an idea that drives basic research, leading (where successful) to non-clinical, pre-clinical, and clinical research, and from there (where successful) to improvements and licensing for sale and use for treatment within the market and subsequent surveillance (or pharmacovigilence). ${ }^{[9]}$ Clinical research can involve so-called 'translational' research or the 'from bench-to-bedside' approach that aims to turn laboratory experiments (here in pharmaceuticals) through clinical research into marketable products. In all there are four phases of clinical trials. Phase I trials use between 20-80 healthy volunteers in order to determine the tolerable dose range of a new drug. In order to evaluate the efficacy and safety of the drug phase II trials involve between 100-300. Phase III trials tend to be multi-centred and might involve up to 10,000 people located in between 10-20 countries. This phase generates more safety and efficacy data. Both phase I and phase II trials tend to involve subjects who have the disease or condition to be treated. Phase IV trials are used to generate more safety and efficacy data, but postmarketing of the drug. This phase can involve millions of people.

In 2001 clinical trials for pharmaceuticals became the subject of EU law through the adoption of the CTD. This legal instrument required Member States to set standards for the planning, performance, reporting, and archiving of research for new pharmaceuticals or 'medicinal products' (see the CTD's full name ${ }^{[1]}$ ). Member States were also required to establish systems of monitoring and inspection in relation to good clinical practice (GCP), many of which are further concretised in subsequent legislation. ${ }^{[10]}$ In short, the CTD provided the standards that apply to the production of data that is used to authorise the marketing of 'medicinal products' within the EU's internal market. The internal market is defined in Article 26(2) TFEU as, 'an area without internal frontiers in which the free movement of goods, persons, services and capital is ensured' (the establishment of the internal market is required by Article 3(3) TEU). Market authorisation is subject to further EU legislation (which I outline below). The legal foundation for the adoption of any EU legislation is in the (EU) Treaties, which comprise a skeletal Treaty on European Union (TEU) that is fleshed out in the Treaty on the Functioning of the European Union (TFEU). EU competence in respect of the internal market is shared with the Member States (under Article 4(2)(a) TFEU). What is now Article 114 TFEU provides the basis for the adoption of harmonising legislation for the establishment and functioning of the internal market, ${ }^{8}$ which therefore includes that on clinical trials and market authorisation (I return to this common legal basis and discuss its significance in relation to the CTR below).

A core focus of the CTD was on ensuring compliance with the Helsinki Declaration' ${ }^{[11]}$ (Helsinki) ethics-based protections for human research subjects, including their informed consent and research ethics committees that determine the permissibility of involving human subjects in the first place.

\footnotetext{
${ }^{7}$ Clinical trials refer to a broader category of trials of pharmaceuticals and medical techniques and practices in a clinical setting.

${ }^{8}$ Where the EU has competence any legislation adopted must also be justified by the principles of subsidiarity and proportionate under Article 5(3) TEU and Article 5(4) TEU respectively.
} 
Within the Helsinki Declaration the ethical permissibility of involving research subjects is tied to the scientific enterprise of creating, refining and advancing scientific knowledge ${ }^{[12]}$ in order to 'improve preventive, diagnostic and therapeutic interventions (methods, procedures and treatments)' (para 9) (emphasis added). To this end the interests of the subjects must not be subordinated to the interests of society. A calculation of risk and benefit is deployed to ensure the research subject is not worse off for being involved than she would have been otherwise.

\section{B Rationale for Adopting a 'Regulation' in EU Law}

Experience under the CTD gave rise to concerns that differences in its application in the EU's (now) 28 Member States (up from 15 in 2001, the year of the CTD's adoption) would undermine scientific research. These differences were exacerbated by the 'cumbersome procedures for multi-centre clinical trials in different Member States' leading to an 'impact on academic as well as non-academic research'. ${ }^{[13]}$ In particular, 'Scientific development...suggests that future clinical trials will target more specific patient populations, such as subgroups identified through genomic information. In order to include a sufficient number of patients for such clinical trials it may be necessary to involve many, or all, Member States' (Recital 4 CTR). ${ }^{[14]}$ Consequently, it became necessary to reconsider the legal form or instrument in respect of clinical trials (consistent with the legal basis for internal market legislation under Article 114 TFEU).

As summarised in the CTR, the adoption of a regulation 'would present advantages for sponsors and investigators, for example in the context of clinical trials taking place in more than one Member State, since they will be able to rely on its provisions directly [before national courts]' (emphasis added) (Recital 5 CTR). ${ }^{9}$ By contrast the CTD (as a directive) could only be relied upon directly in very specific circumstances; ${ }^{10}$ which meant that in most cases domestic implementing legislation was applicable. In the case of the United Kingdom, for example, the CTD was adopted into domestic law by its transposition through the Medicines for Human Use (Clinical Trials) Regulations 2004. ${ }^{[15]}$ In short, the adoption of an EU regulation (the CTR) more uniformly harmonises (that is, standardises) and enhances the efficacy and uniformity of EU law across the EU (and in third countries - as noted above clinical trials carried out in them that feed into the EU's clinical trials and market authorisation processes must comply with the requirements of EU law).

\section{Overview of Changes under the Clinical Trials Regulation}

The CTR has a strong scientific rationale (as we have just seen) and it is entwined with an ethical rationale through the continued focus on the protection of human research subjects (embedded throughout and including: Recitals 15, 17, 27, 44, 76 and 80, Article 3 and Chapter V (on protection of subjects and informed consent) CTR). On the basis of this joint rationale the CTR introduces a number of key changes to the law on clinical trials that applies in EU Member States (more specific changes will also be introduced in respect of $\mathrm{GCP}^{11}$ ). The first change under the CTR is the

\footnotetext{
${ }^{9}$ Article 288 TFEU defines directives and regulations and specifies that they can be adopted for the 'exercise of the Union's competences'. A directive is 'binding, as to the result to be achieved, upon each Member State to which it is addressed, but shall leave to the national authorities the choice of form and methods'. By contrast a regulation has 'general application. It shall be binding in its entirety and directly applicable in all Member States'.

10 The Court of Justice of the European Union (CJEU) has found that provided they are sufficiently clear, precise and unconditional the provisions of directives can be relied upon before Member State courts as against the Member State only (that is, not individuals), but only where their deadline for implementation has passed and the Member State has not properly implemented them (Case 71/74 Van Duyn v Home Office [1974] ECR 1337; Case 148/78 Pubblico Ministero v Tullio Ratti [1979] ECR 1629). By contrast the CJEU has found that regulations are capable of being relied upon before Member State courts as against the Member State and individuals, as appropriate, from the date they enter into force and become applicable (as specified in the specific instrument) (Case 39/72 Commission v Italy [1973] ECR 101).

${ }^{11}$ For the state of play at time of publication, see: Implementation measures by the Commission in the context of Regulation (EU) No 536/2014 - overview and state of play. http://ec.europa.eu/health/files/clinicaltrials/overview_clinical_trials.pdf (accessed 9 December 2015).
} 
introduction by the European Medicines Agency (EMA) of an EU portal that serves as a single entry point for the submission of an application for the authorisation of clinical trials to the reporting Member State (Article 5, Article 16 and Article $80 \mathrm{CTR}^{12}$ ) and an EU database for the storage of the application and related data (Article 81 CTR). There is a single set of application documents and a two-part application process. Part I centres on the necessity of the trial and the balance of risk and benefit of participation by human research subjects. Part I is led by the reporting Member State and jointly assessed by all Member States that have trial sites (Article 6 CTR referring to Chapter V). Part II centres on ensuring compliance with the requirements for informed consent and recruitment of research subjects, rewarding or compensating research subjects, data protection, suitability of those involved in conducting the trial and trial sites, and damage compensation. Compliance with these requirements is assessed separately by each of the Member States where there is a trial site (Article 7 CTR). The assessment of the clinical trial authorisation application and the work of Research Ethics Committees is subject to strict deadlines. ${ }^{13}$ Legal certainty for small and medium sized enterprises (so-called SMEs) and academics, the main sponsors of clinical trials, is improved through the extension of the tacit agreement principle to the entire authorisation process 'in order to ensure that timelines are adhered to' (Recital 8 CTR). ${ }^{14}$

Reporting of clinical trial results is also simplified through their submission to the EU portal for storage on the EU database. Transparency is improved through the public availability of all information (in principle ${ }^{15}$ ) on the clinical trials application and reporting of results submitted via the EU portal and placed in the database (especially under Article 37(4) CTR). ${ }^{16}$ Increased public availability is important for medical professionals, researchers and patients who seek to access, for example, the data on the safety and efficacy of licensed pharmaceuticals or simply to find out what has and has not been trialled and the results. Supervision and enforcement of EU law on clinical trials in Member States and third countries has also been reinforced (Chapter XIII CTR).

Finally, where applications for the authorisation of clinical trials make reference to data derived from trials carried out in third countries, those trials must adhere to standards that are 'equivalent' to those found in the CTR (Article 25(5) CTR). Further, the trials referred to must have been registered in a public register which is a primary or partner registry of, or a data provider to, the World Health Organisation's International Clinical Trials Registry Platform (or WHO ICTRP) (Article 25(6)(1) CTR). These changes build on the requirements in the Community code relating to medicinal products for human use (Community code). ${ }^{[16]}$ The requirements apply to clinical trials data produced in compliance with the CTR (formerly the CTD) as the evidence base for market authorisation. The Community code provides that in relation to third countries, clinical trials conducted in them that

\footnotetext{
${ }^{12}$ In the first instance the trial sponsor shall propose the reporting Member State. In the event that this proposal is declined more detailed rules determine which Member State shall report.

${ }^{13}$ For example, under Article 5(3) CTR the reporting Member State must validate the application 'Within 10 days from the submission of the application dossier', and under Article 6(4) CTR that Member State must 'submit, through the EU portal, the final Part I of the assessment report, including its conclusion, to the sponsor and to the other Member States concerned within 45 days from the validation date'.

${ }^{14}$ An example of tacit agreement that follows on from Article 5(3) CTR (ibid) is that found in Article 5(4) CTR: 'Where the reporting Member State has not notified the sponsor within the period referred to in...[Article 5(3)], the clinical trial applied for shall be deemed to fall within the scope of this Regulation and the application dossier shall be considered complete' (emphasis added).

${ }^{15}$ Confidentiality of the information can be justified on the grounds specified in Article 81(4) CTR, including the protection of commercially confidential information and the protection of personal data.

${ }^{16}$ In particular, Article 37(4)(1)-(2) CTR provides that regardless of the outcome of a clinical trial the sponsor 'shall submit to the EU database a summary of the results of the clinical trial' (as detailed in Annex IV) and a layperson summary (as detailed in Annex V) within one year from the end of a clinical trial in all Member States concerned. Article 37(4)(4) CTR provides where the 'clinical trial was intended to be used for obtaining a marketing authorisation for the investigational medicinal product, the applicant for marketing authorisation shall submit to the EU database the clinical study report within 30 days after the day the marketing authorisation has been granted, the procedure for granting the marketing authorisation has been completed, or the applicant for marketing authorisation has withdrawn the application'. The clinical study report is submitted in addition to the summary of results.
} 
provide data used in an application for market authorisation are subject to standards that are 'equivalent' to (rather than the same as) those applicable in the Member States under the CTR (formerly the CTD). ${ }^{17}$

Further discussion of these specific changes, in particular on the satisfactoriness of ethical protections, ${ }^{[17]}$ lies outside the scope of this article. Instead, my aim is to point out how the CTR has implications for public health that arise from its specific priorities and aims and the wider purposes it reflects and serves. But the changes are far from unimportant to that discussion. In the following I link the significance of the CTR's legal form and the changes it introduces to the achievement of broader programmatic priorities. After which I explain how these are reflected in the CTR's place and role in the pharmaceutical development pipeline and its market-oriented purposes and aims. In light of this legal and political context the new regulation shall gain particular significance in that it becomes clearer how it facilitates the market availability of pharmaceuticals and supports the achievement of the EU's broader market-oriented priorities, while undermining public health objectives.

\section{Situating EU Law and Policy on Clinical Trials: Deeper Market-Oriented Priorities, Purposes and Aims}

\section{A Programmatic Priorities}

Concerns over differences in the application of the law on clinical trials become acute when they not only jeopardise the efficacy and uniformity of EU law, but also the achievement of specific marketoriented purposes and aims, and with them broader programmatic priorities; ie the market availability of new 'medicinal products' and all that hinges on them. It is this concern for markets that ultimately drives and justifies the adoption of the CTR and its modifications of EU law on clinical trials, but not without detrimental consequences for public health objectives. The EU's programmatic priorities provide the broad steer and direction for EU law and policy across all domains, including EU law and policy on clinical trials and the wider pharmaceutical development pipeline. In the 2000 European Council Lisbon Strategy ${ }^{[18]}$ research was presented as 'the driver for the production and exploitation of knowledge [making it] above all a linchpin in the implementation of the Lisbon strategy to make Europe the most dynamic and competitive, knowledge-based economy in the world, capable of sustaining economic growth, employment and social cohesion, ${ }^{\text {[19] }}$ (emphasis added). The Lisbon Strategy is part of the so-called 'knowledge triangle' of research, education and innovation ${ }^{[20]}$ that constitutes the European Research Area. The latter aims to 'reinvigorate research in Europe,[21] through EU funding of research and development. The focus is on enabling discourse between researchers in different Member States in order to foster the economic competitiveness of European industry, and integration. ${ }^{[22]}$ Subsequent iterations of the Lisbon Strategy have gradually narrowed the focus to generating economic growth and jobs, ${ }^{[23]}$ especially after the recent European financial crisis, which led in 2010 to the Commission's Europe 2020 strategy that sought to invigorate economic growth. ${ }^{[24-27]}$

A key Europe 2020 flagship initiative is the innovation union, which 'aims to maximise the EU's capacity for innovation and research and channel it towards societal challenges. The European Commission's aim is to make Europe a world-leader in developing innovative ways to promote active and healthy ageing - a challenge common to all European countries' ${ }^{[28]}$ (emphasis added, except for 'active and healthy ageing'). Noteworthy here is how innovation is linked to research, and this is then directed at tackling societal challenges. Societal optimisation including in relation to health is aimed at the economy - it is to 'boost and improve the competitiveness of the markets for innovative products and services that respond to the ageing challenge both at EU and global level, thus creating new opportunities for businesses' ${ }^{[28]}$ (emphasis added). Funding to support the programmatic

\footnotetext{
${ }^{17}$ Article 8(3)(ib) provides that these particulars shall include a 'statement to the effect that clinical trials carried out outside the European Union meet the ethical requirements of Directive 2001/20/EC' (emphasis added). Annex I, point 8 clarifies that these clinical trials are must be carried out 'on the basis of principles, which are equivalent to the provisions of Directive 2001/20/EC. They shall be carried out in accordance with the ethical principles that are reflected, for example, in the Declaration of Helsinki’ (emphasis added).
} 
priorities in the seventh (and final) Framework Programme, FP7, ${ }^{[29]}$ was directed at research ${ }^{[30]}$ including in biomedicine ${ }^{18}$ - in order to drive future growth instead of as a means of increasing knowledge and understanding per se. The same orientation is found in (the current) Horizon 2020. ${ }^{[31]}$ Within Horizon 2020 (and FP7 before it) funding is limited by the need to ensure 'added value'. Translational research, ie bringing innovations into the EU's marketplace or internal market is an area where the EU can add value, including in relation to clinical trials. Indeed, since 'the translation of basic discoveries into clinical applications is one of the main objectives of this theme [in FP7 - and now Horizon 2020], clinical research, including clinical trials, is expected to be a major tool used in the funded projects' ${ }^{\text {[32] }}$ (emphasis added).

Even when health is apparently the focus, such as in 2007's Together for Health: A Strategic Approach for the EU 2008-2013 ${ }^{[33]}$ (Together for Health), it is again linked to economic priorities. For instance, it is noted 'This Strategy reinforces the importance of health in policies such as the Lisbon Strategy for Growth and Jobs, emphasising the links between health and economic prosperity' (p 2) (emphasis added). In other words, Together for Health 'supports the overall Europe 2020 strategy'[34] for economic growth. Funding to support Together for Health under the EU's health programme, now in its third iteration (for 2014-2020), ${ }^{[35]}$ is directed at meeting the priorities of Europe 2020. For instance, '[i]n line with the objectives of the Europe 2020 Strategy, the Programme should focus on a set of well-defined objectives and actions with clear, proven Union added value, and concentrate support on a smaller number of activities in priority areas ${ }^{[35]}$ (Recital 5) (emphasis added) including health. As with Horizon 2020 funding, this is seen in the focus is on translational research such as clinical trials 'by promoting, where relevant, the uptake of innovative breakthroughs resulting from research in the health sector' ${ }^{[35]}$ (Recital 21). This vision is clearly beneficial for the 'big pharma' ${ }^{\text {[36] }}$ dominated pharmaceuticals industry, which enjoyed a boom period in the 1990s but is now struggling to deliver sufficient numbers of new 'blockbuster drugs'. Supporting clinical trials for translation into marketable pharmaceuticals seeks to enhance the EU's internal market, develop an innovative and competitive industry, ${ }^{[37]}$ and in turn support the EU's project of European integration.

\section{B Developing Pharmaceuticals for the Market}

The way in which clinical trials are made integral to the development and ultimately the marketing of pharmaceuticals in order to meet the EU's programmatic priorities is especially apparent in the alignment of the objective of clinical trials with the criteria for market authorisation, such as under the so-called centralised procedure. ${ }^{19}$ There are several other types of procedure for market authorisation within the EU's internal market ${ }^{[38]}$ and (as summarised above) each of them requires compliance with the Community code and it is this that forms the link with clinical trials. That is because the Community code mentions clinical trials data as the basis for the market authorisation of pharmaceutical treatments on the grounds of their quality, safety and efficacy (embedded throughout the Community code).

The very definition of clinical trials in the CTR (and the CTD before it) highlights their alignment to the requirements for market authorisation under the Community code. Under the CTR clinical trials are clarified as being a type of clinical study ${ }^{20}$ that is an investigation:

'in relation to humans intended: (a) to discover or verify the clinical, pharmacological or other pharmacodynamic effects of one or more medicinal products; (b) to identify any adverse

\footnotetext{
${ }^{18}$ Research into biomedical applications is highlighted in the FP7 objectives, in such references as 'the development and validation of new therapies[...]diagnostic tools and medical technologies'. See [30].

${ }^{19}$ Of course, a clinical trial might not be intended to generate data for market authorisation, for instance where the objective is simply to widen the knowledge base on treatments.

${ }^{20}$ Article 2(2)(2) CTR provides 'clinical study' 'means any investigation in relation to humans intended: (a) to discover or verify the clinical, pharmacological or other pharmacodynamic effects of one or more medicinal products; (b) to identify any adverse reactions to one or more medicinal products; or (c) to study the absorption, distribution, metabolism and excretion of one or more medicinal products; with the objective of ascertaining the safety and/or efficacy of those medicinal products'.
} 
reactions to one or more medicinal products; or (c) to study the absorption, distribution, metabolism and excretion of one or more medicinal products; with the objective of ascertaining the safety and/or efficacy of those medicinal products' (Article 2(2)(1) CTR). ${ }^{21}$ (Emphasis added)

The similar focus on the quality, safety and efficacy of pharmaceuticals (ie 'medicinal products') in the CTR and Community code rather than a wider test of 'comparative therapeutic efficacy' and genuine need (a point I return to later) is unsurprising. Indeed, legal consistency across these instruments is important in order to ensure their joint efficacy and uniform application as part of the pharmaceutical development pipeline that facilitates the marketing of new pharmaceuticals (approval figures are important for communicating success and performance). ${ }^{[39-40]}$

\section{Renewed Significance of the Common Legal Basis of EU Law on Clinical Trials and Market Authorisation}

The similar focus in EU clinical trials and market authorisation legislation and its orientation towards the market is facilitated by the aforementioned common legal basis in Article 114 TFEU. Further attention to this basis underscores the purposes and aims of EU law in these connected areas; and the way in which the basis is used in respect of the CTR in order to meet the EU's broader programmatic priorities. Article 114(3) TFEU requires the Commission to take 'as a base a high level of protection' including inter alia health. This is a more specific instantiation of Article 9 TFEU, a provision of general application which provides 'the Union shall take into account requirements linked to ... a high level of ... protection of human health' (emphasis added) in the definition and implementation of its policies and activities, which of course includes clinical trials and market authorisation. The EU also has competence to support Member State actions in respect of the protection and improvement of health (Article 6(a) TFEU), but while Article 168 TFEU provides the legal basis for the adoption of supporting legislation it excludes any harmonisation (Article 168(5) TFEU).

The importance of the internal market and the protection of human health can be seen in slightly different but nevertheless related ways in both the Community code and CTR. Under the Community code the 'essential aim of any rules governing the production, distribution and use of medicinal products must be to safeguard public health" ${ }^{[16]}$ (Recital 2) (emphasis added). But this aim is immediately followed by the qualification that it 'must be attained by means which will not hinder the development of the pharmaceutical industry or trade in medicinal products within the Community [now Union] ${ }^{\text {[16] }}$ (Recital 3) (emphasis added). The principle aim here is the establishment and functioning of the internal market - and the protection of human health is constructed in a very specific way such that it is effectively subordinated to market interests. Further, reflecting the narrow criteria for market authorisation and the purpose of clinical trials the public health implications of pharmaceuticals are confined to their safety.

While the CTD, like the other pieces of legislation discussed here, was based on the EU's competence in relation to the internal market, similar statements of purposes and aims are not present. However, under the CTR the link between clinical trials and pharmaceutical product marketing is specified and tightened through its foundation on the dual legal basis of Articles 114 TFEU and Article 168(4)(c) TFEU. These provisions provide objectives that are 'pursued simultaneously' and 'one is not secondary to another' (Recital 82 CTR). As regards Article 114 TFEU, the CTR:

'harmonises the rules for the conduct of clinical trials in the Union, therefore ensuring the functioning of the internal market in view of the conduct of a clinical trial in several Member States, the acceptability throughout the Union of data generated in a clinical trial and submitted in the application for the authorisation of another clinical trial or of the placing on the market of a medicinal product, and the free movement of medicinal products used in the context of a clinical trial' (Recital 82 CTR). (Emphasis added)

\footnotetext{
${ }^{21}$ This definition is very similar to that under Article 2(a) CTD.
} 
In a derogation from the limits on EU competence for the protection and improvement of health, Article 168(4)(c) TFEU builds on the shared competence in respect of the common safety concerns in respect of public health matters (Article 4(2)(k) TFEU). With this provision as a legal basis the CTR is used to set:

'high standards of quality and safety for medicinal products by ensuring that data generated in clinical trials are reliable and robust, thus ensuring that treatments and medicines which are intended to be an improvement of a treatment of patients build on reliable and robust data. Moreover, this Regulation sets high standards of quality and safety of medicinal products used in the context of a clinical trial, thus ensuring the safety of subjects in a clinical trial' (Recital 82 CTR). (Emphasis added)

This statement might imply that a key aim of the CTR is to produce clinical trials data that will demonstrate a new pharmaceutical is an improvement over what is already available. However, this is not necessarily the case. As the EMA explains in its 'soft law' guidance 'it is not necessary for the benefit-risk profile of an experimental medicine to [be] at least as favourable as the benefit-risk profile of any or all established medicines in order to receive marketing authorisation, ${ }^{\text {'41] }}$ (emphasis added). For example, producing a new pharmaceutical that has fewer side-effects can be useful, as can having multiple equally effective medicines available as a way of tackling resistance to medication. Consistent with the criteria for market authorisation (quality, safety and efficacy) clinical trials need only at the bare minimum ensure that pharmaceuticals are as good as or at least no worse than existing products. In other words, in order to be licensed the new pharmaceutical need not be an improvement over what is already available and clinical trials need only demonstrate that is the case. ${ }^{[4-5]}$

In sum, the deeper and overall purpose and aim of the CTR is to get pharmaceuticals through the development pipeline and onto the market as quickly as possible. But the CTD inhibited the production of data on product safety (particularly where multi-site trials are required) and undermined the market availability of new pharmaceuticals. This (it is supposed) in turn impacted negatively on sales, the return on research and development costs, and the corporate bottom line. Specific decisions about the CTR - the selection of the legal form of a regulation, how to utilise the dual legal basis and the changes introduced - are made and justified by the need to speed up the pharmaceutical development pipeline and the achievement of wider market-oriented programmatic priorities. Indeed, as stated in the CTR: 'The timelines for assessing an application dossier for clinical trials should be sufficient to assess the file while, at the same time, ensuring quick access to new, innovative treatments and ensuring that the Union remains an attractive place for conducting clinical trials' (Recital 8 CTR) (emphasis added).

\section{Conclusion}

While product safety is essential, the focus on it in EU clinical trials and market authorisation law and policy is not in itself sufficient to bring about the vision of the scientific enterprise in this area, ie creating improvements in public health that are to the benefit of society at large. Instead, the CTR ensures that knowledge creation through clinical trials fits better with scientific developments and wider law and policy on the pharmaceutical development pipeline. As part of the pipeline clinical trials are oriented towards producing a version of economic optimisation that supports private commercial profitability through the marketing of 'more of the same, if not worse'. To some extent this might be understood as a consequence of the relative strength of the EU's competence in relation to the internal market as compared to public health. However, the direction and orientation of EU clinical trials law and policy reflects broader programmatic priorities. It is in light of these priorities that the focus on safety matters becomes more easily viewed as a specific decision about how to make use of EU competence in respect of pharmaceutical development and marketing within the internal market.

Nevertheless, since the EU is under an obligation to take into account the protection of human health at a high level in all areas of its activities, it could yet adopt internal market harmonisation legislation that ensures better protection of human health. In other words, it remains possible for the EU (through 
its legislature) to make a different decision: one that better realises the achievement of public health objectives. Crucially the EU could decide to recast the criteria for market authorisation, and align clinical trials to it, so that there is a focus throughout the development pipeline on the safety and comparative efficacy of new pharmaceuticals as well as a genuine need for them. ${ }^{22}$ Such a change would be more in the spirit of the scientific enterprise and go some way to rebalancing the prioritisation of interventions and public health problems, and better achieving overall public health outcomes. This change would also mean the EU better fulfils its responsibilities for the internal market and public health. But this decision remains a distant prospect while the EU's programmatic priorities are focused on the internal market and a very particular version of economic optimisation rather than meeting important and wider public health needs and objectives.

\section{References}

[1] European Parliament, Council of the European Union. Directive 2001/20/EC of the European Parliament and of the Council of 4 April 2001 on the approximation of the laws, regulations and administrative provisions of the Member States relating to the implementation of good clinical practice in the conduct of clinical trials on medicinal products for human use. Official Journal of the European Union 2001;L121:34-44 .

[2] European Parliament, Council of the European Union. Regulation (EU) 536/2014 on of the European Parliament and of the Council of 16 April 2014 on clinical trials on medicinal products for human use, and repealing Directive 2001/20/EC. Official Journal of the European Union 2014;L158:1-76.

[3] Petrini, What is the role of Ethics Committees after Regulation (EU) 536/2014?; Westra, Ambiguous articles in new EU Regulation may lead to exploitation of vulnerable research subjects.

[4] Flear ML. Clinical trials abroad: the marketable ethics, weak protections and vulnerable subjects of EU law. In: Albors-Llorens A, Armstrong K, Gehring MW, eds. Cambridge Yearbook of European Legal Studies, Vol 16 2013-2014. Oxford: Hart Publishing 2014:75-107.

[5] Flear ML. Governing Public Health. Oxford: Hart Publishing 2015.

[6] Abraham J. Evolving sociological analyses of "pharmaceuticalisation": a response to Williams, Martin and Gabe. Sociol Health Illn 2011;33:726-728.

[7] Williams SJ, Gabe J and Davis P. The sociology of pharmaceuticals: progress and prospects. Sociol Health Illn. 2008;30(6):813-824.

[8] Global Forum for Health Research. The 10/90 Gap in Health Research. Geneva: GFHR 1999.

[9] Bache G, Flear ML and Hervey TK. The defining features of the European Union's approach to regulating new health technologies. In: Flear ML et al, eds. European Law and New Health Technologies. Oxford: Oxford University Press 2013:7-45.

[10] European Commission. Directive 2005/28/EC of 8 April 2005 laying down principles and detailed guidelines for good clinical practice as regards investigational medicinal products for human use, as well as the requirements for authorisation of the manufacturing or importation of such products. Official Journal of the European Union 2005;L91:13-19.

[11] World Medical Association. Declaration of Helsinki. Ethical principles for medical research involving human subjects (6th revision). World Medical Association, 2008.

\footnotetext{
${ }^{22}$ Although the EU cannot adopt harmonisation legislation in the field of public health, it is possible for the protection of public health to be a decisive factor in the adoption of legislation on the basis of Article 114 TFEU, provided it has as its genuine object the improvement in the conditions for the establishment and functioning of the internal market. See: Case C-376/98 Germany v European Parliament and Council [2000] ECR I-8419.
} 
[12] Marks HM. The Progress of Experiment: Science and therapeutic reform in the United States, 1900-1990. Cambridge: Cambridge University Press 1997.

[13] European Commission. Safe, Innovative and Accessible Medicines: a renewed vision for the pharmaceutical sector. COM(2008) 666 final, 8. Reflected in Recital 4 CTR.

[14] Jackson E. Law and the Regulation of Medicines. Oxford: Hart Publishing 2012:ch 8.

[15] Statutory Instrument No 1031 (2004).

[16] European Parliament, Council of the European Union. Directive 2001/83/EC of 6 November 2001 on the Community code relating to medicinal products for human use. Official Journal of the European Union 2001;L311:67-128.

[17] Kahn JP et al. Beyond Consent: Seeking Justice in Research. Oxford: Oxford University Press 1998.

[18] Council of the European Union. Presidency Conclusions - Lisbon European Council, 23rd and 24th March. Brussels: 2000. See: Armstrong K. Governance and constitutionalism after Lisbon. In: JCMS Symposium: EU Governance After Lisbon. J Common Mark Stu 2008;46:413-450.

[19] European Commission. Building the ERA of Knowledge for Growth. COM(2005) 118 final, 2.

[20] European Commission. Innovation Tomorrow Innovation Policy and the Regulatory Framework: Making Innovation an Integral Part of the Broader Structural Agenda. Prepared by Louis Lengrand and Associés, PREST (University of Manchester) and ANRT (France). Innovation papers No 28. Luxembourg: Office for Official Publications of the European Communities 2002; European Commission. Putting Knowledge into Practice: A Broad-based Innovation Strategy for the EU. $\operatorname{COM}(2006) 502$ final.

[21] European Commission. Towards a European Research Area. COM(2000) 6 final, 5.

[22] Gusma`o R. Research networks as a means of European integration. Tech in Science 2003;23:386-393.

[23] Kok W. Facing the Challenge: The Lisbon Strategy for Growth and Employment. Report from the High Level Group Chaired by Wim Kok. Brussels: European Commission 2004.

[24] Europe 2020. http://ec.europa.eu/europe2020/index_en.htm (accessed 9 December 2015).

[25] European Commission. Smart Regulation in the European Union. COM (2010) 543 final.

[26] European Commission. Europe 2020 Flagship Initiative Innovation Union. COM (2010) 546 final.

[27] European Commission. Europe 2020. A Strategy for Smart, Sustainable and Inclusive Growth. COM (2010) 2020 final.

[28] Europe 2020 - for a healthier EU. http://ec.europa.eu/health/europe_2020_en.htm (accessed 9 December 2015).

[29] European Parliament, Council of the European Union. Decision No 1982/2006/EC of the European Parliament and of the Council of 18 December 2006 concerning the Seventh Framework Programme of the European Community for Research, Technological Development and Demonstration Activities (2007-2013). Official Journal of the European Union 2006;L412:1-41.

[30] Proposed Priorities for Innovative Health Research 2012. http://ec.europa.eu/research/health/pdf/fp7-health-2012-orientation-paper_en.pdf $\quad$ (accessed 9 December 2015).

[31] European Parliament; Council of the European Union. Regulation (EU) No 1291/2013 of the European Parliament and of the Council of 11 December 2013 establishing Horizon 2020 - the 
Framework Programme for Research and Innovation (2014-2020) and repealing Decision No 1982/2006/EC. Official Journal of the European Union 2013;L347:104-173.

[32] Medical Research in the Enion. https://webgate.ec.europa.eu/socialinnovationeurope/en/magazine/health-and-wellbeing/articlesreports/health-innovation-funding-under-fp7.

[33] European Commission. White Paper, Together for Health: A Strategic Approach for the EU 2008-2013. COM(2007) 630 final; European Commission. Commission Staff Working Document Accompanying White Paper, Together for Health: A Strategic Approach for the EU 2008-2013. SEC(2007) 1376. For an overview of initiatives, see European Commission. Commission Staff Working Document, Report on European Governance (2003-2004). SEC(2004) 1153.

[34] Health strategy. http://ec.europa.eu/health/strategy/policy/index_en.htm.

[35] European Parliament, Council of the European Union. Regulation (EU) 282/2014 of the European Parliament and of the Council of 11 March 2014 on the establishment of a third Programme for the Union's action in the field of health (2014-2020) and repealing Decision 1350/2007/EC. Official Journal of the European Union 2014;L86:1-13.

[36] Goldacre B. Big Pharma. London: Harper Perennial 2009.

[37] European Commission. A Stronger European-Based Pharmaceutical Industry for the Benefit of the Patient - A Call for Action. $\operatorname{COM(2003)~} 383$ final; European Commission. Putting Knowledge into Practice: A Broad-based Innovation Strategy for the EU. COM(2006) 502 final.

[38] For an overview see: Authorisation procedures for medicinal products. http://ec.europa.eu/health/authorisation-procedures_en.htm (accessed 9 December 2015).

[39] EMA Recommends 81 Medicines for Marketing Authorisation in 2013. http://www.ema.europa.eu/ema/index.jsp?curl=pages/news_and_events/news/2014/01/news_detail_0 02006.jsp\&mid=WC0b01ac058004d5c1 (accessed 9 December 2015).

[40] Howie LJ et al. A comparison of FDA and EMA drug approval: implications for drug development and cost of care. Oncology 2013; http://www.cancernetwork.com/oncologyjournal/comparison-fda-and-ema-drug-approval-implications-drug-development-and-costcare\#sthash.SO6MTTLW.dpuf (accessed 9 December 2015).

[41] European Medicines Agency. Reflection Paper on the Need for Active Control in Therapeutic Areas Where Use of Placebo is Deemed Ethical and One or More Established Medicines are Available. EMA/759784/2010:3-4. 